\title{
Prevalence screening for ovarian cancer in postmenopausal women by CA 125 measurement and ultrasonography
}

\author{
Ian Jacobs, Ann Prys Davies, Jane Bridges, Isabel Stabile, Toby Fay, Adrian Lower, \\ J G Grudzinskas, David Oram
}

\begin{abstract}
Objective-To assess the performance of the sequential combination of serum CA 125 measurement and ultrasonography in screening for ovarian cancer.
\end{abstract}

Design-The serum CA 125 concentration of each subject was determined and those with a concentration $\geqslant 30 \mathrm{U} / \mathrm{ml}$ were recalled for abdominal ultrasonography. If ultrasonography gave abnormal results surgical investigation was arranged. Volunteers were followed up by annual postal questionnaire. departments, ovarian cancer screening clinic.

Subjects-22000 women volunteers who were postmenopausal and aged over 45 years.

Main outcome measures-Apparent sensitivity, specificity, positive predictive value, years of cancer detected.

Results -41 women had a positive screening result and were investigated surgically. 11 had ovarian cancer (true positive result) and 30 had other disorders or no abnormality (false positive result). Of the 21959 volunteers with a negative screening result, eight subsequently presented clinically with ovarian cancer (false negative result) and 21951 had not developed ovarian cancer during follow up (apparent true negative result). The screening protocol achieved a specificity of $99.9 \%$, a positive predictive value of $26.8 \%$, and an apparent sensitivity of $78.6 \%$ and $57.9 \%$ at one year and two year follow up respectively. The estimated number of years of cancer detected by the prevalence screen was 1.4 years.

Conclusions-This screening protocol is highly specific for ovarian cancer and can detect a substantial proportion of cases at a preclinical stage. Further investigation is required to determine the effect of the screening protocol on the ratio of early to late stage disease detected and on mortality from ovarian cancer.

Gynaecological Oncology Unit and Academic Unit of Obstetrics and

Gynaecology, Royal London Hospital, London E1 1BB

Ian Jacobs, research fellow Ann Prys Davies, research fellow

Jane Bridges, research fellow Isabel Stabile, research fellow

Toby Fay, research fellow Adrian Lower, lecturer J G Grudzinskas, professor David Oram, consultant

Correspondence to: Dr I Jacobs, Department of Obstetrics and Gynaecology, Cambridge University, Rosie Maternity Hospital, Cambridge CB2 2SW.

BMF 1993;306:1030-4

The natural course of ovarian cancer is characterised by late presentation, poor response to current treatment, and a poor prognosis. Over $70 \%$ of patients have metastatic disease at the time of presentation and the overall survival rate is less than $25 \%$. In contrast, the small proportion of patients with early stage disease at diagnosis have a relatively good prognosis with five year survival rates over $70 \%$. That detection of early stage disease may decrease mortality for ovarian cancer has long been recognised. The identification of the CA 125 antigen $^{12}$ and the application of real time ultrasonography to ovarian imaging ${ }^{3}$ suggested that screening for early stage ovarian cancer may be

We have reported the results of a pilot study of screening for ovarian cancer incorporating CA 125 measurement, ultrasonography, and pelvic examination. ${ }^{4}$ The results of that study and a subsequent study
Setting-General practice, occupational health

using ultrasonography alone ${ }^{5}$ showed that no individual test has sufficient specificity to achieve an acceptable positive predictive value on screening postmenopausal women. Our preliminary results ${ }^{4}$ and the report of Einhorn et al indicate that high levels of specificity can be achieved when a population of apparently healthy postmenopausal women are screened with a sequential combination of CA 125 measurement and ultrasonography. This paper reports the results of a prevalence screen of 22000 postmenopausal women to assess further the performance of CA 125 measurement and ultrasonography in screening for ovarian cancer.

\section{Subjects and methods}

Women aged over 45 years and with more than 12 months' amenorrhoea were invited to volunteer for the study by articles describing the project in the national press, leaflets distributed by the occupational health departments of companies collaborating with the project, and postal invitations from the age-sex register of 40 general practices in England, Scotland, and Wales collaborating with the project. Volunteers were eligible for the study only if they fulfilled the following criteria: (a) age 45 years or older, (b) more than one year of amenorrhoea, $(c)$ no history of ovarian cancer, $(d)$ no bilateral oophorectomy, $(e)$ resident in the United Kingdom, and $(f)$ not currently known to have active malignancy of any type. Women with a malignancy last treated more than one year before volunteering and with no evidence of recurrence were not excluded from participation. Once eligibility was established appointments were sent by post along with a detailed fact sheet describing the study, a consent form, and data sheet. Appointments were made for three months after the initial contact to avoid the screening project being used as an alternative to attending a general practice surgery. If volunteers were found to be ineligible when they attended for their registration visit they were excluded at that time. Volunteers recruited through the press attended our hospital's ovarian cancer screening clinic for registration and those recruited through occupational health departments or general practice were seen at their place of work or general practitioner's surgery respectively. feasible.

\section{Methods}

After giving informed consent volunteers completed a questionnaire and had blood taken by venepuncture for CA 125 radioimmunoassay. Blood samples were allowed to clot at room temperature and then centrifuged at $3000 \mathrm{rpm}$ for 10 minutes. The serum was separated, aliquoted, and stored at $-20^{\circ} \mathrm{C}$. The CA 125 radioimmunoassay was performed within four weeks of storing the samples according to the manufacturer's instructions (CA 125 radioimmunoassay; Abbott Laboratories, Chicago). The detection limit of the assay was $7 \mathrm{U} / \mathrm{ml}$ and the intra-assay and interassay coefficients of variation at $30 \mathrm{U} / \mathrm{ml}$ were $8.5 \%$ and $9 \cdot 1 \%$ respectively. A serum CA 125 concentration of $30 \mathrm{U} / \mathrm{ml}$ 
or more was defined as abnormal. This cut off had previously been shown to achieve high specificity in combination with ultrasonography ${ }^{4}$ and was the lowest concentration with satisfactory assay performance. If the serum CA 125 concentration was normal, volunteers were informed within six weeks of their registration visit. If the serum CA 125 level was abnormal, volunteers were recalled for real time ultrasonography. formed with a $3.5 \mathrm{MHz}$ transducer either at the Royal London Hospital (by a gynaecologist with two years' ultrasound experience or a consultant radiologist) or at another hospital collaborating with the project (by a consultant radiologist). Ovarian diameter was measured in three dimensions and ovarian volume calculated by the formula for an ovoid described by Campbell et al. ${ }^{3}$ Ultrasound findings were classified as abnormal if ovarian volume was greater than $8.8 \mathrm{ml}$ or ovarian echogenicity was not uniform. If the ultrasound findings were equivocal (for example, suspicious ovarian morphology but ovarian volume $<8.8 \mathrm{ml}$ ) ultrasonography was repeated every four to six weeks. If the ovaries could not be identified but no pelvic abnormality was apparent the ultrasound findings were classified as normal. Volunteers with an abnormal ultrasound scan result were advised to consult their general practitioner, who was informed independently of the scan report, and referral to a gynaecologist for further management was arranged. Women with a normal scan result were followed up every three months with repeat serum CA 125 measurements.

All volunteers were followed up annually after their initial visit by postal questionnaire. If no reply was received within one month further efforts to complete follow up were made by telephone, through the next of kin, and through the general practitioner. Volunteers were asked whether they had required any medical attention since the initial visit and if they had, details were obtained from the hospital or general practice.

\section{DEFINITIONS AND STATISTICAL ANALYSIS}

Specificity was defined as the percentage of volunteers without ovarian cancer who had negative results on screening. Apparent sensitivity was defined as the percentage of volunteers who had positive screening results and were known to have developed ovarian cancer after a stated length of follow up. The study design provided an apparent rather than an absolute estimate of sensitivity for two reasons. Firstly, it was not possible to establish whether women with a false negative screening result had ovarian cancer at the time of registration or had developed the disease subsequently. Secondly, it was not possible to establish the

FIG 1-Distribution of serum $C A$ 125 concentration in 19 postmenopausal women with ovarian cancer diagnosed at screening or subsequently (•) and 328 women with $C A 125$ concentrations above $30 \mathrm{U} / \mathrm{ml}$ who did not have cancer diagnosed (O). The 21653 women with $C A 125$ concentration below $30 \mathrm{U} / \mathrm{ml}$ who did not develop cancer are not shown

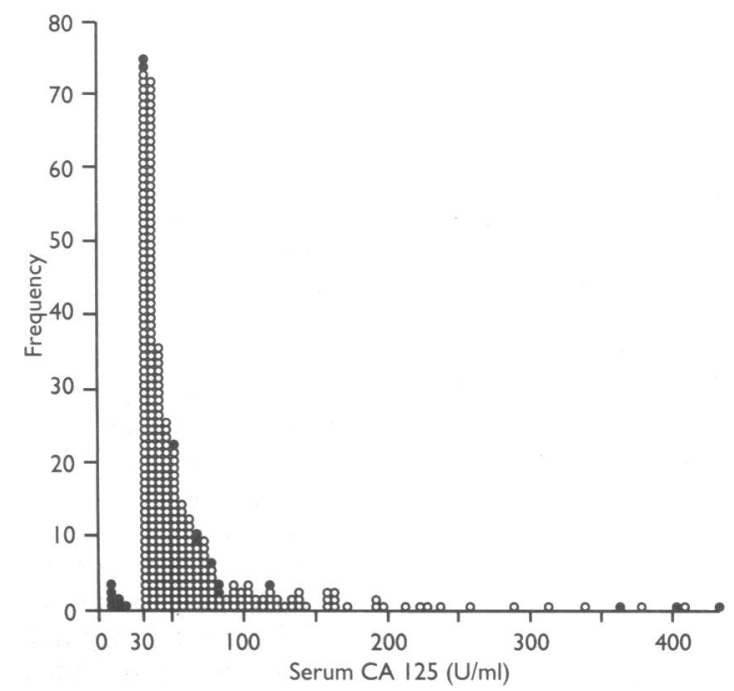

Real time transabdominal ultrasonography was per-

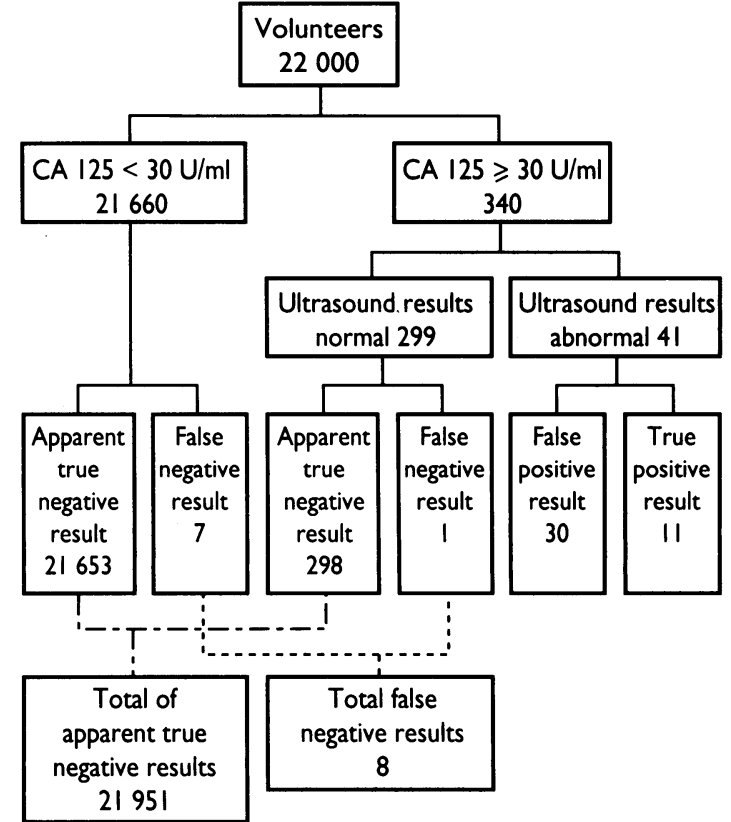

FIG 2-Summary of study findings in 22000 postmenopausal women

TABLE I-Age distribution, expected incidence of ovarian cancer, and actual incidence among 22000 women

\begin{tabular}{|c|c|c|c|c|}
\hline $\begin{array}{l}\text { Age } \\
\text { group } \\
\text { (years) }\end{array}$ & $\begin{array}{c}\text { No of } \\
\text { volunteers }\end{array}$ & $\begin{array}{c}\text { Expected } \\
\text { incidence of } \\
\text { ovarian cancer } \\
\text { (rate per } \\
100000 / \text { year) }\end{array}$ & $\begin{array}{c}\text { Expected } \\
\text { No of cases } \\
\text { a year }\end{array}$ & $\begin{array}{c}\text { No of } \\
\text { cases } \\
\text { detected }\end{array}$ \\
\hline $45-49$ & 2531 & $20 \cdot 5$ & 0.52 & 1 \\
\hline $50-54$ & 6409 & 33.0 & $2 \cdot 11$ & 2 \\
\hline $55-59$ & 7109 & $36 \cdot 4$ & 2.59 & 4 \\
\hline $60-64$ & 3544 & $46 \cdot 7$ & 1.67 & 2 \\
\hline $65-69$ & 1677 & $47 \cdot 7$ & $0 \cdot 80$ & 1 \\
\hline $70-74$ & 516 & $46 \cdot 7$ & 0.24 & 1 \\
\hline $75-79$ & 125 & $47 \cdot 9$ & 0.06 & 0 \\
\hline $80-84$ & 87 & $48 \cdot 7$ & 0.04 & 0 \\
\hline$>84$ & 2 & $43 \cdot 0$ & 0.00 & 0 \\
\hline Total & 22000 & & 8.03 & 11 \\
\hline
\end{tabular}

number of women with ovarian cancer at the time of screening who remained unidentified and would present clinically during further follow up. Positive predictive value was defined as the percentage of women with positive screening results who had ovarian cancer. The expected number of cases of ovarian cancer in the study population was estimated from Office of Population Censuses and Surveys cancer incidence data. ${ }^{7}$ Confidence intervals for the observed number of cases of ovarian cancer were calculated by assuming a standard Poisson distribution. The study was approved by the Royal London Hospital ethics committee.

Results

A total of 22000 volunteers were recruited over two years: 8049 attended the Royal London Hospital, 4110 participated at work, and 9841 attended their general practitioner's surgery. Table I shows the age distribution of the study population. The median age was 56 (range 45-85) years. The length of amenorrhoea ranged from 1 to 43 years with a median of $6 \cdot 2$ years. The mean number of pregnancies beyond 28 weeks' gestation was $2 \cdot 2$ (range $0-14$ ). Of the women, 4450 had had hysterectomy with conservation of one or both ovaries and 892 women had a history of malignancy (403 of breast cancer) but no evidence of recurrent disease at recruitment.

Figures 1 and 2 show the distribution of serum CA 125 concentration and a summary of the study results. Nineteen cases of ovarian cancer occurred in the study population, of which 11 were detected by 
screening and eight presented clinically during follow up. There was $98 \cdot 7 \%$ compliance with one year follow up and at the time of this report two year follow up was still in progress $(57 \%$ complete).

A total of 21951 women had a negative screening result and have not to our knowledge developed ovarian cancer. Of these women with apparently true negative results, 21653 had a serum CA 125 concentration $<30 \mathrm{U} / \mathrm{ml}$. The remaining $298 \mathrm{had}$ a raised serum CA 125 concentration and were called for ultrasonography. One of these 298 women refused a scan, 75 had equivocal findings at their initial scan which became normal on repeat scanning, and 222 had normal findings at the initial scan. One or both ovaries could not be identified in $8 \%(24 / 297)$ of the women with normal ultrasound scan findings.

Seven volunteers with a serum CA 125 concentration $<30 \mathrm{U} / \mathrm{ml}$ subsequently had ovarian cancer diagnosed clinically. Two cases were diagnosed within 12 months of the registration visit, four cases between 12 and 18 months, and one case at 22 months (table II). One volunteer with an initial serum CA 125 concentration of $80 \mathrm{U} / \mathrm{ml}$ declined to attend for an ultrasound scan and presented clinically with stage III clear cell carcinoma of the ovary six months after her registration visit. There were no false negative results among the group of volunteers with a raised serum CA 125 concentration and normal ultrasound scan findings.

No evidence of ovarian cancer was found at laparoscopy or laparotomy in 30 of the 41 women who had positive screening results. Of these women, 25 had benign pelvic disease, two had no abnormality, two had carcinoma of the fallopian tube, and one had abdominal carcinomatosis of uncertain origin (table III). Eleven women with a raised serum CA 125 concentration and an abnormal result on ultrasonography were found to have invasive epithelial ovarian cancer at laparotomy (table IV). Three had stage I disease, one had stage II disease, and seven had stage III or IV disease. In four of the seven cases of advanced stage disease the initial ultrasound scan gave equivocal results and surgery was not done until a repeat scan appeared abnormal.

Table $\mathrm{V}$ summarises the performance of the screening programme. The sequential combination of CA 125 measurement and ultrasonography achieved a specificity of $99.9 \%$, a positive predictive value of $26.8 \%$, and an apparent sensitivity of $78.6 \%$ at one year follow up and $57.9 \%$ at two year follow up (incomplete).

The expected incidence of ovarian cancer for a population of the same age and sex as the study

TABLE II-Details of women with false negative results on screening

\begin{tabular}{llcc}
\hline Stage & $\quad$ Histology & $\begin{array}{c}\text { Serum } \\
\text { CA 125 } \\
\text { (U/ml) }\end{array}$ & $\begin{array}{c}\text { Interval from } \\
\text { registration to } \\
\text { clinical diagnosis } \\
\text { (months) }\end{array}$ \\
\hline III & Clear cell cystadenocarcinoma & $80^{\star}$ & 6 \\
III & Granulosa cell tumour & 7 & 8 \\
I & Serous cystadenocarcinoma & 7 & 12 \\
III & Mucinous cystadenocarcinoma & 16 & 13 \\
I & Serous cystadenocarcinoma & 7 & 13 \\
I & Serous cystadenocarcinoma & 12 & 17 \\
I & Serous cystadenocarcinoma & 14 & 18 \\
I & Clear cell cystadenocarcinoma & 9 & 22 \\
\hline
\end{tabular}

*This woman declined to return for an ultrasound scan.

TABLE III-Details of women with false positive results on screening

\begin{tabular}{lcc}
\hline Diagnosis & No of women & $\begin{array}{c}\text { Serum CA } 125 \\
(\mathrm{U} / \mathrm{ml})\end{array}$ \\
\hline Benign ovarian cyst & 17 & $30-150$ \\
Endometriosis & 3 & $40-73$ \\
Pelvic adhesions & 3 & $30-60$ \\
Fallopian tube carcinoma & 2 & $35-95$ \\
Abdominal carcinomatosis & 1 & 120 \\
Fimbrial cyst & 1 & 60 \\
Hydrosalpinx & 1 & 45 \\
No abnormality & 2 & $30-40$ \\
\hline
\end{tabular}

TABLE IV-Details of women with true positive results on screening

\begin{tabular}{llcc}
\hline Stage & \multicolumn{1}{c}{ Histology } & $\begin{array}{c}\text { Serum } \\
\text { CA 125 } \\
\text { (U/ml) }\end{array}$ & $\begin{array}{c}\text { No of equivocal } \\
\text { scans before } \\
\text { abnormal scan }\end{array}$ \\
\hline Ia & Clear cell cystadenocarcinoma & 32 & 0 \\
Ia & Clear cell cystadenocarcinoma & 33 & 0 \\
Ib & Serous cystadenocarcinoma & 80 & 0 \\
IIa & Serous cystadenocarcinoma & 119 & 0 \\
III & Serous cystadenocarcinoma & 68 & 2 \\
III & Serous cystadenocarcinoma & 78 & 0 \\
III & Mucinous cystadenocarcinoma & 66 & 2 \\
III & Poorly differentiated carcinoma & 360 & 1 \\
III & Poorly differentiated carcinoma & 54 & 0 \\
IV & Poorly differentiated carcinoma & 436 & 1 \\
IV & Serous cystadenocarcinoma & 400 & 2 \\
\hline
\end{tabular}

TABLE V-Performance of screening for ovarian cancer by measuring CA 125 concentration and ultrasonography in 22000 women

\begin{tabular}{|c|c|c|c|}
\hline & \multirow[b]{2}{*}{ Positive screening result } & \multicolumn{2}{|c|}{ Negative screening result } \\
\hline & & 1 year & 2 years \\
\hline $\begin{array}{l}\text { Cancer present } \\
\text { Cancer absent }\end{array}$ & $\begin{array}{l}11(\mathrm{a}) \\
30(\mathrm{c})\end{array}$ & $\begin{array}{r}3(\mathrm{~b}) \\
21956(\mathrm{~d})\end{array}$ & $\begin{array}{r}8(\mathrm{~b}) \\
21951 \text { (d) }\end{array}$ \\
\hline
\end{tabular}

Specificity $(d /(d+c))$ was $99.9 \%$ and positive predictive value $(a /(a+c))$ $26.8 \%$. The apparent sensitivity $(a /(a+b))$ was $78.6 \%$ after one year and $57.9 \%$ after two years.

population can be estimated from cancer incidence data collected by the Office of Population Censuses and Surveys (table I). ${ }^{7}$ Table I also lists the number of cases of ovarian cancer detected in each age group. Eleven cases of ovarian cancer were detected by the screening programme in a population with an expected incidence of 8.0 cases a year. The estimated number of years of cancer detected was therefore $11 / 8=1 \cdot 4(95 \%$ confidence interval 0.7 to $2 \cdot 5$ ).

\section{Discussion}

As women with a positive screening result for ovarian cancer require surgical investigation, the changes detected by screening must be highly specific for the presence of malignancy. A test resulting in more than 10 surgical procedures for each case of ovarian cancer detected (positive predictive value $<10 \%$ ) would not be acceptable in clinical practice. The incidence of ovarian cancer in women aged 45 years or over in England and Wales is 40 per 100000 per year. ${ }^{7}$ For this population an annual screening test for ovarian cancer, even with $100 \%$ sensitivity, would require $99.6 \%$ specificity to achieve a positive predictive value of $10 \%$. The level of specificity required to achieve a positive predictive value of $10 \%$ could be decreased by screening a population with a higher incidence of ovarian cancer, such as women with a family history of the disease. However, such an approach would include only $1-10 \%$ of ovarian cancer patients in the screened population (depending on the definition of family history). Our pilot study ${ }^{4}$ and the report by Campbell et $a p$ showed that no individual test can achieve a specificity of $99 \cdot 6 \%$. The results of this prevalence screen confirm the high specificity and positive predictive value of a sequential screening protocol incorporating CA 125 concentration as a primary test and ultrasonography as a secondary investigation.

We expected that sensitivity of the screening protocol would be more difficult to assess than specificity. Firstly, without subjecting all patients to oophorectomy it was impossible to establish with certainty which women had ovarian cancer at the time of the initial screen and which were disease free. Consequently, some women classified as having false negative results may have been disease free at the initial screen and have developed ovarian cancer subsequently, while some women with apparently true negative results may have had ovarian cancer at the time of the initial screen and have not yet been 
diagnosed clinically. Secondly, it was not possible to achieve complete compliance with follow up. False negative cases of cancer may have occurred among the small proportion of volunteers who did not respond to one year follow up. Thirdly, as the study was a prevalence screen, the distribution of the stages of ovarian cancer in the population was fixed and could not be influenced by the effectiveness or otherwise of the screening protocol. If the study population contained $\mathrm{x}$ early stage and $\mathrm{y}$ advanced stage cases of ovarian cancer the ratio of early to advanced stage disease detected would be $\mathrm{x}: \mathrm{y}$ even if the screening programme was $100 \%$ sensitive. The relatively small proportion of early stage cancer detected $(4 / 11)$ must be interpreted in this context and may not reflect the ability of the screening programme to detect early stage disease. If screening with CA 125 measurement and ultrasonography is an effective method of early diagnosis the ratio of early to late stage disease will be increased at follow up screening of our population.

Despite these limitations our results confirm the suggestion from previous retrospective studies that measuring CA 125 can detect a substantial proportion of early stage ovarian cancers. CA 125 concentrations in preoperative samples from patients with clinically diagnosed ovarian cancer are raised in $50.0 \%$ of stage 1 and $90.0 \%$ of stage II cancers. ${ }^{8}$ Zurawski et al found serum CA 125 concentrations above $30 \mathrm{U} / \mathrm{ml}$ in six of 12 stored samples collected up to 18 months before the diagnosis of ovarian cancer, and 14 of 59 samples collected more than 60 months before diagnosis had a serum CA 125 concentration above $30 \mathrm{U} / \mathrm{ml} .^{9}$ The sensitivity of CA 125 for preclinical early stage disease is unlikely to be greater than the $50 \%$ documented for clinically diagnosed stage I disease but would seem to be at least $33 \%$. Four cases of early stage ovarian cancer (stage I and II) were detected and if all eight false negative cases had early stage ovarian cancer at the time of the initial screen the detection rate would have been four out of $12(33 \%)$.

\section{VALUE OF SCREENING PROGRAMME}

An index of the potential value of a screening programme can be obtained from the years of cancer detected by a prevalence screen. The years of cancer detected estimates the average lead time before diagnosis by screening. We estimated that the lead time of our screening protocol was about 1.4 years. This estimate is based on an assumption that the age related incidence of ovarian cancer in the study population is similar to the national incidence for each age group provided by Office of Population Censuses and Surveys data. Women with a family history of ovarian cancer were probably overrepresented in the study population compared with the general population as they have a strong motivation to volunteer. As family history is an established risk factor for ovarian cancer this would tend to overestimate the duration of the CA 125 positive preclinical phase. The proportion of women with a previous hysterectomy was higher than would be expected in the general population. This factor would tend to underestimate the preclinical phase as available evidence suggests that the risk of ovarian cancer is reduced among women who have had a hysterectomy with ovarian conservation. ${ }^{1011}$ The number of years of cancer detectable by CA 125 could be greater than 1.4 years as some of the 298 volunteers with a raised CA 125 concentration but normal ultrasound appearances may develop ovarian cancer on long term follow up.

Several possible strategies exist for improving the performance of screening tests for ovarian cancer. Firstly, there is preliminary evidence that transvaginal ultrasonography can achieve greater specificity and sensitivity than abdominal scanning. ${ }^{12}$ Secondly,
Bourne et al have suggested that transvaginal Doppler colour flow imaging of ovarian vasculature may improve the specificity of ultrasound screening for ovarian cancer [see paper by Bourne et al p 1025]. ${ }^{13}$ Thirdly, there is evidence that combinations of complementary tumour markers may improve sensitivity and specificity. ${ }^{1+19}$ Fourthly, the specificity of screening by measuring serum CA 125 concentration can be improved by analysis of serial determinations. ${ }^{1920}$ Finally, recent advances in molecular genetics have raised the possibility that a high risk population suitable for screening may be defined by genetic markers. ${ }^{21}$ Each of these approaches requires further investigation.

Our results have confirmed the high specificity of the combination of CA 125 and ultrasonography and suggest that the lead time before clinical diagnosis achieved by this screening protocol is greater than one year. We are continuing follow up screens to establish the sensitivity of the screening protocol for preclinical ovarian cancer as well as the relation between the screening interval and the ratio of early to late stage cancers detected. If the results are sufficiently encouraging a randomised controlled study will be performed to assess the impact of the screening protocol on mortality from ovarian cancer.

This research project was supported by grants from Birthright, the British Medical Association (T P Gunton Award) and the Gynaecology Cancer Research Fund. We thank Mrs Mary Butcher, Mrs Liz Thompson, Mrs Pru Weideman, Miss P Legon, Mrs P Kemsley, Dr Patricia Last, Dr Leila Kapadia, and Dr Murray Bruce for their contributions to the project. The collaboration of the following general practitioners and their colleagues was essential to the study. Dr V Bali (Rhondda), Dr D Bannatyne (Harrogate), Dr M E Barnard (Edgware), Dr J Blacklin (Greasby), Dr C J Browne (Tipton), Dr C E Cock (Choppington), Dr Crick (Hemsby), Dr M Davies (Cookham), Dr V M de-Hoxar (Heswall), Dr G Dowling (Biggin Hill), Dr E Eaton (Markfield), Dr J C Ewart (Bletchley), Dr C Gilbert (Colchester), Dr C Goldwyn (Twickenham), Dr M C N Henchy (Bretton), D N Higson (Hove), Dr R D Last (Somerset), Dr R Leisching (Great Holm), Dr A Martin (Ayr), Dr M Monks (Warrington), Dr Naidoo (Oxford), D I Nelemans (Bournemouth), Dr J M Phillips (Swindon), Dr D J Pilling (Blackpool), Dr D C Rawlings (Coleford), Dr C D Sansom (Thingwall), Dr L Singer (Southend), Dr A R Snead (Shropshire), Dr A Thake (Handsworth), and Dr G J Tyler (Letchworth).

1 Bast RC, Feeney M, Lazarus H, Nadler L, Colvin RB, Knapp RC. Reactivity of a monoclonal antibody with human ovarian carcinoma. $f$ Clin Invest of a monoclonal

2 Bast RC, Klug TL, St John E, Jenison E, Niloff JM, Lazarus H, et al. A radioimmunoassay using a monoclonal antibody to monitor the course of epithelial ovarian cancer. N Engl f Med 1983;309:169-71.

3 Campbell S, Goswamy R, Goessens L, Whitehead MI. Real time ultrasonography for determination of ovarian morphology and volume. Lance 1982; : $425-6$

4 Jacobs IJ, Stabile I, Bridges J, Kemsley P, Reynolds C, Grudzinskas JG, et al. Multimodal approach to screening for ovarian cancer. Lancet 1988;i:268-71.

5 Campbell S, Bhan V, Royston P, Whitehead MI, Collins WP. Transabdomina ultrasound screening for early ovarian cancer. $B M F$ 1989;299:1363-7.

6 Einhorn N, Siovall K, Knapp RC, Schoenfeld DA, Hall P, Eklund G, et al. Prospective evaluation of serum CA 125 levels for early detection of ovarian cancer. Obstet Gynecol 1992;80:14-8.

7 Office of Population Censuses and Statistics. Cancer statistics, registrations: cases of diagnosed cancer registered in England and Wales. London: HMSO, of diagnosed $1983: 26-31$.

8 Jacobs IJ, Bast RC, The CA 125 tumour associated antigen; a review of the literature. Hum Reprod 1989;4:1-12.

9 Zurawski VR, Orjaseter H, Andersen A, Jellum E. Elevated serum CA 125 levels prior to diagnosis of ovarian neoplasia; relevance for early detection of ovarian cancer. Int 9 Cancer 1988;42:677-80.

10 Annegers JF, Strom H, Decker DG, Dokerty MB, O'Fallon WM. Ovarian cancer: incidence and case control study. Cancer 1979;43:723-9.

11 Hildreth NG, Kelsey JL, LiVolsi VA, Fischer DB, Holford TR, Mostow ED et al. An epidemiologic study of epithelial carcinoma of the ovary. $\mathrm{Am}$ Epidemiol 1981;114:398-405.

12 Van Nagell JR, Higgins RV, Donaldson ES, Gallion HH, Powell DE, Pavlik EJ, et al. Transvaginal sonography as a screening method for ovarian cancer. A report on the first 1000 cases screened. Cancer 1990;65:573-7.

13 Bourne T, Campbell S, Steer C, Whitehead MI, Collins WP. Transvaginal colour flow imaging: a possible new screening technique for ovarian cancer. colour flow imaging: a possi

14 Bast RC Jr, Knauf S, Epenetos A, Dhokia B, Daly L, Tanner M, et al. Coordinate elevation of serum markers in ovarian cancer but not in benign Coordinate elevation of serum mark.
disease. Cancer 1991;68:1758-63. 
15 Ward BG, Cruickshank DJ, Tucker DF, Love S. Independent expression in serum of three tumour-associated antigens: CA 125, placental alkaline phosphatase and HMFG2 in ovarian carcinoma $\mathrm{Br} \%$ Obstet Gymacol 1987;94:696-8.

16 Schwartz PE, Chambers SK, Chambers JT, Gutmann J, Katopodis N, Foemmel R. Circulating tumor markers in the monitoring of gynecologic malignancies. Cancer 1987;60:353-61.

17 Cole LA, Nam J-H, Chambers JT, Schwartz PE. Urinary gonadotrophin fragment, a new tumor marker. II. Differentiating a benign from malignant pelvic mass. Gynecol Oncol 1990;36:391-4.

18 Kacinski BM, Chambers SK, Carter D, Filderman AE, Stanley ER. The macrophage colony stimulating factor CSF-1, an auto- and paracrine tumour cytokine is also a circulating 'tumor marker' in patients with ovarian, endometrial and pulmonary neoplasms. In: Dinarello CA, Kluger M],
Powanda MC, Oppenheim JJ, eds. The physiological and pathological effects of cytokines. New York: Wiley-Liss, 1990:393-400.

19 Jacobs IJ, Oram DH, Bast RC Jr. Strategies for improving the specificity of screening for ovarian cancer with tumor associated antigens CA 125 , CA 15-3, and TAG 72.3. Obstet Gynecol 1992;80:396-9.

20 Zurawski VR, Sjovall K, Schoenfeld DA, Broderick SF, Hall P, Bast RC Jr et al. Prospective evaluation of serum CA 125 levels in a normal population, et al. Prospective evaluation of serum CA 125 levels in a normal population, ovarian cancer. Gynecol Oncol 1990;36:299-305.

21 Narod SA, Feunteun J, Lynch HT. Familial breast-ovarian cancer locus on chromosome 17q12-q23. Lancet 1991;338:82-3.

(Accepted 2 March 1993)

\section{Serevent nationwide surveillance study: comparison of salmeterol with salbutamol in asthmatic patients who require regular bronchodilator treatment}

Win Castle, Rick Fuller, John Hall, James Palmer

Abstract

Objective-To compare safety of salmeterol and salbutamol in treating asthma.

Design-Double blind, randomised clinical trial in parallel groups over 16 weeks.

Setting-General practices throughout the United Kingdom.

Subjects -25180 patients with asthma considered to require regular treatment with bronchodilators who were recruited by their general practitioner $(\mathbf{n}=3516)$.

Interventions-Salmeterol (Serevent) $\quad(50 \mu g$ twice daily) or salbutamol ( $200 \mu \mathrm{g}$ four times a day) randomised in the ratio of two patients taking salmeterol to one taking salbutamol. All other drugs including prophylaxis against asthma were continued throughout the study.

Main outcome measures-All serious events and reasons for withdrawals (medical and non-medical) whether or not they were considered to be related to the drugs.

Results-Fewer medical withdrawals due to asthma occurred in patients taking salmeterol than in those taking salbutamol $\left(2.91 \% v 3.79 \% ; \chi^{2}=13.6\right.$, $p=0 \cdot 0002)$. Mortality and admissions to hospital were as expected. There was a small but nonsignificant excess mortality in the group taking salmeterol and a significant excess of asthma events including deaths in patients with severe asthma on entry. Use of more than two canisters of bronchodilator a month was particularly associated with the occurrence of an adverse asthma event.

Conclusions-Treatment over 16 weeks with Glaxo Group Research Greenford, Middlese UB6 0HE

Win Castle, director of international drug surveillance Rick Fuller, director of respiratory medicine

Allen and Hanbury's, Uxbridge, Middlesex UB11 1BT

John Hall, medical director

Glaxo Research Institute, Research Triangle Park, North Carolina, United States

James Palmer, vice president of clinical research

Correspondence to: Dr Fuller. the control of asthma may be worse during treatm with regular fenoterol compared with intermittent $\beta$ agonists. ${ }^{4}$ More recently the safety of $\beta$ agonists has come under scrutiny. ${ }^{5}$ Firstly, a rebound increase in bronchial reactivity has been observed in research that studied regular use of $\beta$ agonists, ${ }^{6}$ although this has not been a consistent finding. ${ }^{7}$ Secondly, a reduction in lung function was reported during a two year study of salbutamol and ipratropium bromide, ${ }^{8}$ although again this has not been found in other studies. ${ }^{9}$

In addition, epidemiological studies have shown an increase in deaths due to asthma, which some authors have related to the use of $\beta$ agonists, ${ }^{10}$ and a more detailed case control study has related increased use of $\beta$ agonists to an increased risk of death from asthma." For each additional canister administered each month the odds ratio increased by $2 \cdot 6$. Causal relations have been suggested but the high use of $\beta$ agonists probably merely reflects severity of asthma and that these patients with more severe asthma are at greater risk of death. Such a relation between severe asthma and the risk of death has indeed been shown in other epidemiological studies. ${ }^{12}$

The development of a long acting $\beta$ agonist $^{13}$ for which regular use is recommended has raised some concerns. Our study compared the safety of salmeterol ( $50 \mu \mathrm{g}$ Serevent twice daily) with that of salbutamol (200 $\mu \mathrm{g}$ four times a day) in a large number of patients with asthma $(>25000)$. Because of the large numbers we could compare our results with events related to asthma throughout the United Kingdom..$^{14} 15$

\section{Subjects and methods}

PROTOCOL

The trial was a randomised, double blind study in parallel groups over 16 weeks. Randomisation from blocks of six was four patients allocated to salmeterol $(50 \mu \mathrm{g}$, two puffs morning and bedtime and two puffs of placebo noon and early evening to retain the blinding) to two patients allocated to salbutamol $(200 \mu \mathrm{g}$, two puffs four times a day). The general practitioners were all given prenumbered treatment packs which they gave to the patients as they were allocated the next consecutive study number. All other drugs including prophylaxis against asthma was continued throughout the study. The supervising general practitioner was asked to prescribe whatever treatment he or she considered appropriate to relieve symptoms. The trial was conducted by 3516 general practitioners and monitored by staff employed by the medical department of Allen and Hanburys.

\section{PATIENTS}

At the first visit of the study patients with asthma were recruited by their general practitioner and randomised. After they had shown effective use of an 